\title{
Ecology of house lizards in the biblical palace of King Solomon
}

\author{
Julián Monge-Nájera \\ julianmonge@gmail.com \\ LABORATORIO DE ECOLOGÍA URBANA, UNED \\ SAN JosÉ, COSTA RICA
}

\begin{abstract}
The Bible refers to house lizards that could not be exterminated, not even from king's palaces (Solomon's Proverbs 30:28). It probably refers to Hemidactylus turcicus, carrier of the deadly Salmonella enterica, of pandemic infamy. Considering the size of Solomon's palace, it could have kept a population of 50 lizards which reproduced from March to August.
\end{abstract}

KEYWORDS: archaeological ecology, historical analysis, biblical herpetology, home ecology, biblical zoology, indoor biome, Israel herpetofauna.

In 1748 English theologian John Gill published his Exposition of the Old Testament, where he comments on a rare biblical passage about an animal that could not be eliminated from human dwellings, not even when the people trying to eradicate them were as wise as King Solomon himself 1 .

King James version referred, in Proverbs 30:28, to house spiders ("The spider taketh hold with her hands, and is in kings' palaces"). This could mean a variety of things, wrote Gill. Maybe that the spider is to be admired because she builds her web as well as if "she understood the rules of mathematics and architecture"; maybe that we should imitate her industriousness, because she rebuilds the web as many times as you destroy it; maybe that the web is "as weak as the hopes of hypocrites" 1.

However, others believed that the correct translation was not spider, but lizard. Gill was aware of this, but doubted that lizards dwelt in palaces; may yes, he added on second thought, because Bellonius and Pliny spoke of lizards that captured insects in doors, windows, and chambers 1.

Modern translations use the second option and read: "a lizard can be caught with the hand, yet it is found in kings' palaces" (Proverbs 30:28, New International Version), which makes more sense considering that the whole section deals with how even small animals can be outside human control and show impressive behaviors beyond our understanding (Figure 1). 


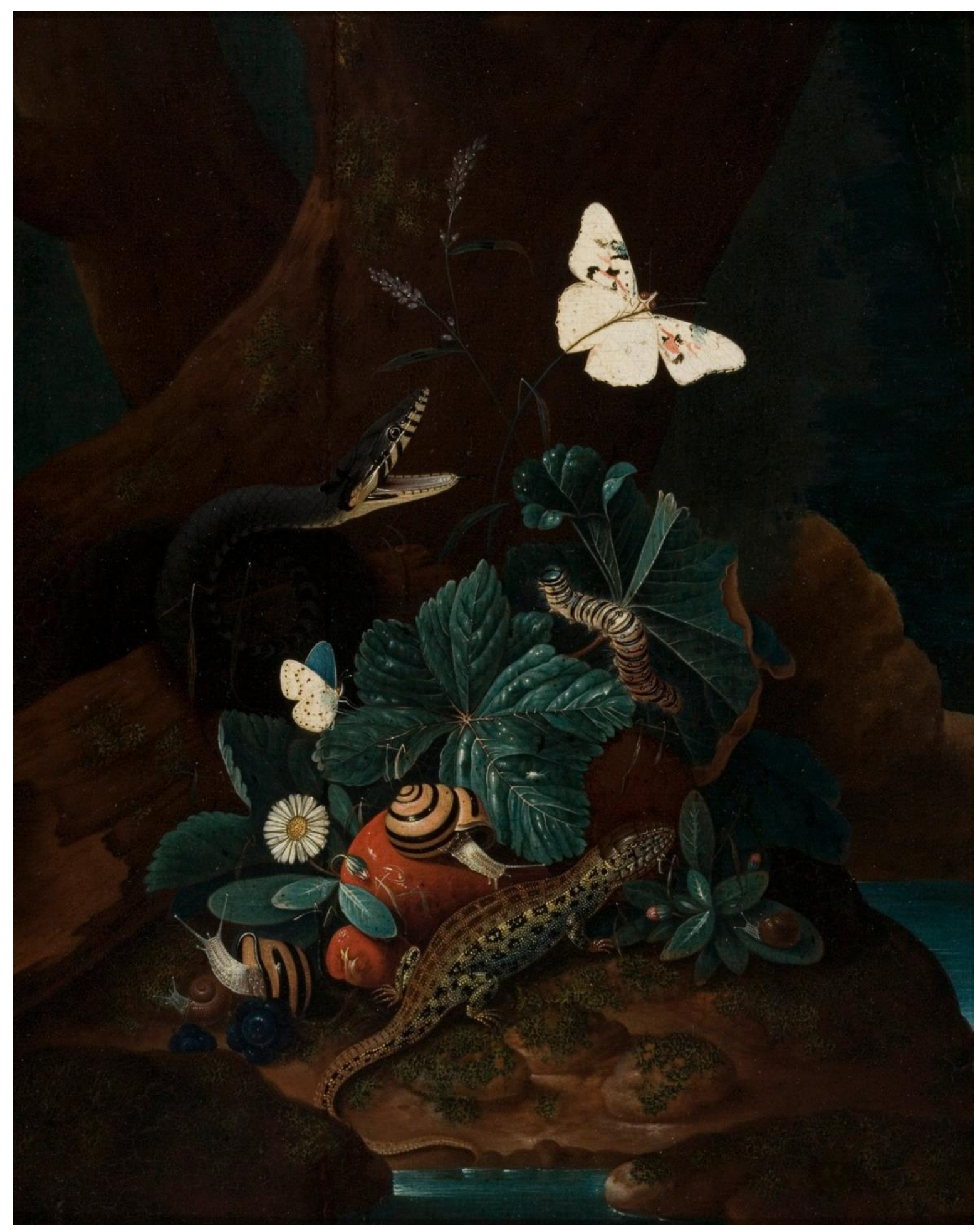

Figure 1. Hidden in the dark, house lizards lived and reproduced in the palaces of biblical kings, beyond the kings' power. Image: Forest Floor Still Life, by Karl Wilhelm de Hamilton (1668-1754), wikimedia.org, https://bit.ly/3cm1QoI

Why would biblical kings be so willing to eliminate the humble lizard from their palaces? 
Because, when they died, their corpses could fall on house items, even on food, and contaminated them:

"The gecko, the monitor lizard, the wall lizard, the skink and the chameleon. Of all those that move along the ground, these are unclean for you. Whoever touches them when they are dead will be unclean till evening" (Leviticus 11:29-30).

The authors of Leviticus were not so far off in their appreciations. They feared some kind of contamination from the corpse, but they also knew that such contamination had its limits: they also mention that seeds that were in contact with the corpses did not produce harmful crops (Leviticus 11:37). Recent scientific research has found that antibiotic-resistant Salmonella enterica 2 is common in some house reptiles and can be deadly at the pandemic level (Figure 2).

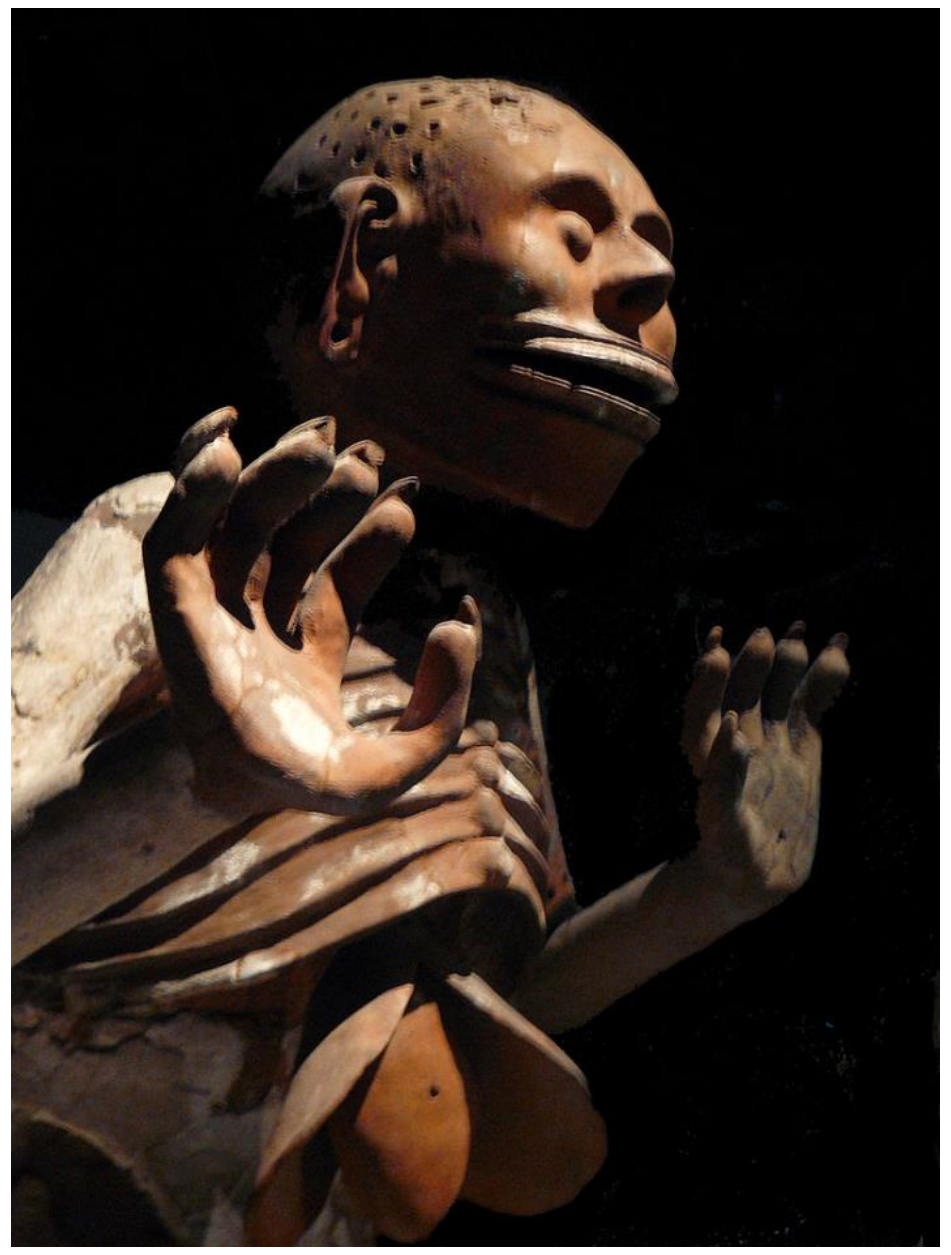

Figure 2. Mediterranean House Geckos can carry the dangerous Salmonella enterica, which was carried to their colonies by the Spaniards and caused millions of deaths during the Cocoliztli Pandemia of Mexico in 1576. Image: Mictlantecuhtli, Aztec God of Death, https://commons.wikimedia.org/wiki/File:Mictlantecuhtli sculpture-2.jpg 
Thousands of years ago, the biblical lizard was part of the large biota that still shares our homes 3 and the central idea is that around the seventh century BCE not even kings could rid their palaces of them. But, which lizards exactly?

Of around 20 species of small lizards currently found in Israel and Palestine, the most likely species that the author of Proverbs knew is the Mediterranean house gecko, Hemidactylus turcicus, a $13 \mathrm{~cm}$ long lizard (Figure 3). Of course, we cannot be certain, but assuming I got the species right, it means that in biblical days, the king's palace was home to a gecko that only came out late at night and was seen eating insects attracted to oil lamp lights.

While condemned by Leviticus 11, in some cultures it is taboo to hurt this species, and this -together with some behavioral and ecological characteristics - may have allowed $H$. turcicus to become invasive in neotropical habitats 4 .

Hidden from King Solomon's eyes, his palace geckos produced several clutches of two eggs from March to August, sometimes in communal nesting areas. They were most active from March to November and on warm nights in winter, and fed on moths attracted to the light of oil lamps, by which some of the biblical texts might have been written. But even though he could not see most of this, the writer of Proverbs 30:28 must have heard them, because they have a high-pitched call, similar to a squeak, with territorial and maybe also courtship functions 5 . 


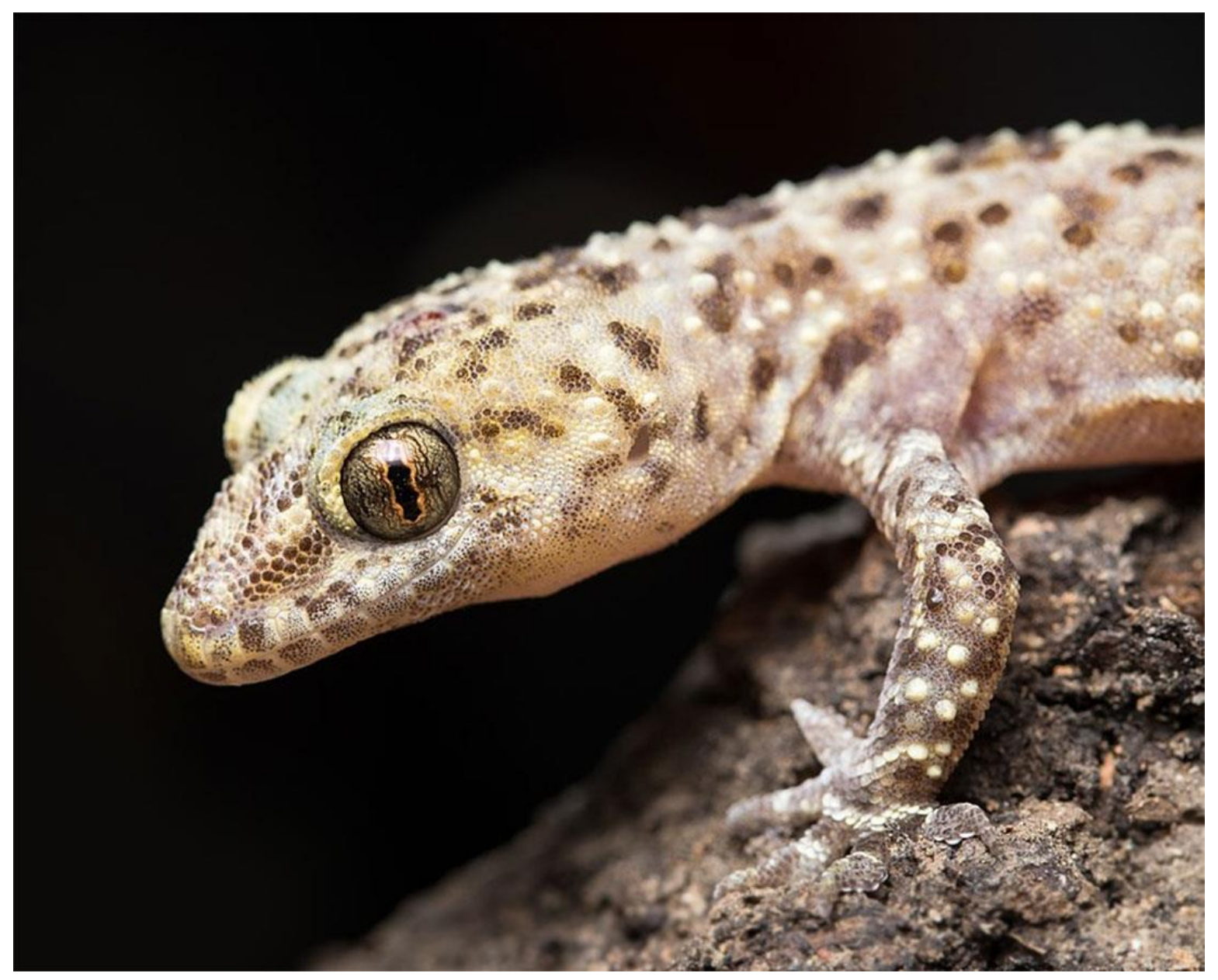

Figure 3. The Mediterranean House Gecko, Hemidactylus turcicus, the probable biblical species now established in Cuba, Mexico and Panama, as well as in the USA. Photograph by K. Kalaentzis, wikimedia.org, https://bit.ly/2WqtUAA

How many geckos lived in King Solomon's palace?

If they had the same density that they reach today, 478 geckos per hectare 6 , and if the palace measured 0,099 hectares as stated in 1 Kings 7:2-3, there were about 50 geckos living with the wisest of kings.

There is no archaeological evidence indicating that King Solomon was, or was not, a real person 7, but whoever wrote the Book of Proverbs knew indoor geckos, and I was surprised to learn how little we know about this species. Now that they are established in the neotropics, they are also available for study by Cuban, Mexican and Panamanian scientists.

\section{REFERENCES}

1Gill, J. (1748). Exposition of the Old Testament. Retrieved from 
https://www.biblestudytools.com/commentaries/gills-exposition-of-the-bible/proverbs-3028.html

${ }_{2}$ Ebani, V. V., et al. (2005). Salmonella enterica isolates from feces of domestic reptiles and a study of their antimicrobial in vitro sensitivity. Research in veterinary science, 78(2), 117-121.

3Martin, L. J., et al. (2015). Evolution of the indoor biome. Trends in Ecology \& Evolution, 30(4), 223-232.

4McCoy, C. J. (1970). Hemidactylus turcicus. Catalogue of American Amphibians and Reptiles (CAAR), 87, 1-2

5Ibrahim, A. A. (2007). Ecology of the Mediterranean Gecko, Hemidactylus turcicus (Linnaeus, 1758) (Reptilia: Gekkonidae), in North Sinai, Egypt. Zoology in the Middle East, 41(1), 41-54.

6Locey, K. J., \& Stone, P. A. (2006). Factors Affecting Range Expansion in the Introduced Mediterranean Gecko, Hemidactylus turcicu. Journal of Herpetology, 40(4), 526-530.

7Millard, A. R. (1991). Texts and archaeology: weighing the evidence. The case for King Solomon. Palestine Exploration Quarterly, 123(1), 19-27. 